\title{
Determination of Ki-67 Defined Growth Fraction by Monoclonal Antibody MIB-I in Formalin-Fixed, Paraffin-Embedded Prostatic Cancer Tissues
}

\author{
Marinus A. Noordzij, Theodorus H. van der Kwast, \\ Gert Jan van Steenbrugge, Wytske M. van Weerden, \\ Maria H.A. Oomen, and Fritz H. Schröder \\ Departments of Urology (M.A.N., G.J.v.S., M.H.A.O., F.H.S., W.M.v.W.) and Pathology \\ (T.H.v.d.K.), Erasmus University, Rotterdam, The Netherlands
}

\begin{abstract}
The applicability of MIB-1, a monoclonal antibody directed against the $\mathrm{Ki}-67$ antigen, was studied in the PC-82 and LNCaP prostatic tumor models at various levels of proliferative activity. Statistically significant correlations were found in LNCaP cultures between Ki-67 and MIB-1 scores $(r=0.84, P<0.001)$, and in PC-82 tumors between MIB-1 scores and paraffin tissue $\mathrm{Ki}-67(\mathrm{pKi}-67)(\mathrm{r}=0.90, P<0.001)$, frozen tissue $\mathrm{Ki}-67$ (fKi-67) $(\mathrm{r}=0.86, P<0.001)$, and BrdU uptake $(\mathrm{r}=0.70, P<0.001)$, respectively. $\mathrm{pKi}-67$ scores were double the fKi-67 scores, which may be due to methodological differences. MIB-1 scores exceeded both the fKi- 67 and pKi-67 scores. The affinity of MIB-1 for the antigen is much higher than the affinity of Ki-67, which may explain the differences. MIB-1 is a promising means of evaluating the presence of only minute amounts of the $\mathrm{Ki}-67$ antigen in paraffin-embedded human tumor material, especially in relatively slowly growing tumors. (C) 1995 Wiley-Liss, Inc.
\end{abstract}

KEY WORDS: proliferative activity, PC-82, LNCaP, BrdU, immunohistochemistry

\section{INTRODUCTION}

Since its description in 1983, much attention has been paid to the mouse monoclonal antibody Ki-67 [1]. Ki-67 is directed against a nuclear antigen expressed in human cells during the $G 1, S, G 2$, and $M$ phases of the cell cycle, but not during the GO phase [2]. Quiescent (G0) cells which enter the cell cycle do not express the antigen in the early G1 phase [2]. The proliferative activity of a number of human tumors, including prostatic carcinoma, has been studied by the application of $\mathrm{Ki}-67$, as investigated by Oomens et al. [3] and reviewed by Brown and Gatter [4]. Routine studies were hampered by the fact that $\mathrm{Ki}-67$ was thought to be applicable only to fresh-frozen tissues. MIB-1 is a recently described mouse monoclonal antibody raised against recombinant parts of the $\mathrm{Ki}-67$ antigen, and it is applicable to routinely processed, paraffin-embedded tissues following antigen retrieval $[5,6]$. It has recently been shown that $\mathrm{Ki}-67$ also reacts with paraffin tissue sections, using this technique [7].
DNA-replicating cells can be identified by a monoclonal antibody to BrdU (bromodeoxy-uridine), a thymidine analogue incorporated into DNA in the $S$ phase of the cell cycle [8]. BrdU-uptake has been studied in human tumors [9-11]. The present study was performed to investigate the applicability of MIB-1 to routinely processed prostate cancer specimens.

Two human prostatic tumor models were used in the present study: the PC-82 xenograft model which is serially transplantable in athymic nude mice [12], and the in vitro LNCaP cell line [13]. The growth rate of both hormone-dependent tumor models can be manipulated by growing the tumors at various an-

Received for publication April 28, 1994; accepted November 11, 1994.

Address reprint requests to M.A. Noordzij, M.D., Department of Urology, Room EE 1000, Division of Urological Oncology, Erasmus University, P.O. Box 1738, 3000 DR Rotterdam, The Netherlands. 
drogen concentrations [14,15]. The potency of using the Ki-67 antibody for monitoring hormonal responses in the PC- 82 tumor has been described previously [16].

In the present study, MIB-1 scores were correlated with fKi-67 (frozen tissue Ki-67), pKi-67 (paraffin tissue Ki-67), and BrdU scores. This was achieved by application of the antibodies to frozen or paraffin tissue sections from the same PC-82 tumor, or to slides with acetone-fixed LNCaP cells. Hormonal manipulation of the PC-82 tumors and LNCaP cells resulted in tissues at various levels of proliferative activity. Also, a number of radical prostatectomy specimens embedded 6-16 years ago were stained with MIB-1 in order to investigate the applicability of MIB-1 to archival clinical tissues.

\section{MATERIALS AND METHODS}

\section{Experimental Models}

PC-82 tumor cells were subcutaneously implanted in nude mice of Balb/c background. Tumor growth was manipulated by implantation of tumor-bearing mice with various androgen levels; tumor growth could be arrested by androgen withdrawal [14]. BrdU $(10 \mathrm{mg} / \mathrm{kg}$ ) was injected intraperitoneally $1 \mathrm{hr}$ prior to sacrifice of the host animal. After sacrifice of the animal, tumor sections were either snap-frozen in liquid nitrogen-chilled isopentanyl $99 \%$ and stored at $-80^{\circ} \mathrm{C}$, or routinely fixed in $4 \%$ formalin in PBS (phosphate-buffered saline, $\mathrm{pH}$ 7.4) and embedded in paraffin. Routinely processed prostatectomy specimens embedded 6-16 years ago were obtained from the Department of Pathology, Dijkzigt Hospital, Rotterdam. To avoid the risk of detachment of cells or tissues from the glass slides, APES (3-aminopropyltriethoxysilane)-coated slides were used in all experiments [17].

LNCaP-FGC (fast-growing colony) cells were seeded on APES-coated slides. The cells were grown in $7.5 \%$ fetal calf serum at standard conditions as described elsewhere [18]. The culture medium from exponentially growing cultures was replaced (after 2 days) by 5\% DCC (dextran-coated charcoal)-treated, i.e., androgen-depleted, serum. Slides were fixed in acetone for $10 \mathrm{~min}$ at $0,24,48,72$, and $96 \mathrm{hr}$ following androgen withdrawal. The $\mathrm{LNCaP}$ experiments were performed in triplicate.

\section{Frozen Tissue Ki-67 (fKi-67) and BrdU Staining}

$\mathrm{Ki}-67$ and BrdU staining procedures have been described previously $[3,8]$. Briefly, monoclonal antibody Ki-67 (DAKO, Glostrup, Denmark) and a monoclonal antibody specific for BrdU (Eurodiagnostics,
Apeldoorn, The Netherlands) were applied to 5- $\mu \mathrm{m}$ thick frozen and paraffin sections, respectively. Ki-67 was diluted $1: 5$ in PBS. Antibody-antigen binding was visualized using an indirect two-step peroxidase method with $\mathrm{DAB}\left(3,3^{\prime}\right.$-diaminobenzidine tetrahydrochloride) as chromogen. Prior to application of the BrdU antibody, these sections were subsequently placed in $2 \mathrm{~N} \mathrm{HCl}$ for 30 min to uncoil the DNA, and in a borate buffer, $\mathrm{pH} \mathrm{8.5,} \mathrm{for} \mathrm{neutralization} \mathrm{[8].}$

\section{Paraffin Tissue Ki-67 (pKi-67) and MIB-I Staining}

The procedure used for MIB- 1 staining is the result of the optimization of the procedure recommended by the manufacturer (Immunotech, Marseille, France). An identical procedure was used for $\mathrm{pKi}-67$ staining, except for the primary antibody. Paraffin PC-82 and prostatectomy sections of $5-\mu \mathrm{m}$ thickness were cut and mounted on APES-coated slides [17]. The slides were kept overnight at $60^{\circ} \mathrm{C}$. After rehydration, the slides were placed in $10 \mathrm{mM}$ citrate buffer adjusted to $\mathrm{pH} 6.0$, after which antigen retrieval was performed in a microwave oven at $700 \mathrm{~W}$ for $15 \mathrm{~min}$ [6]. Distilled water was regularly added to prevent drying of the slides due to evaporation. The slides were allowed to cool down to room temperature, and were subsequently rinsed in PBS. Antigen retrieval was omitted for the acetone-fixed LNCaP cells. To avoid nonspecific staining, both tissue sections and $\mathrm{LNCaP}$ cultures were preincubated for $15 \mathrm{~min}$ at $37^{\circ} \mathrm{c}$ with normal goat serum (DAKO) diluted 1:10 in PBS. Overnight incubation with MIB-1 (Immunotech), diluted 1:200 in $\mathrm{PBS}$, or with $\mathrm{Ki}-67$ (DAKO), diluted 1:10 in PBS, was carried out at $4^{\circ} \mathrm{C}$. After rinsing in PBS, the sections were incubated for $30 \mathrm{~min}$ at room temperature with a 1:400 dilution of biotinylated goat anti-mouse serum (DAKO) in PBS containing 3\% normal goat and 3\% normal human serum. After rinsing in PBS, a final incubation with avidin biotin complex $(\mathrm{ABC})$, consisting of streptavidin and biotinylated horseradish peroxidase diluted in PBS, as described by the manufacturer (DAKO), was performed for $30 \mathrm{~min}$ at room temperature. The staining was visualized with $0.075 \%$ DAB (Fluka, Buchs, Germany) in PBS with $0.08 \%$ hydrogen peroxide as substrate for $7 \mathrm{~min}$. Sections were rinsed in distilled water, and counterstained with Mayers hematoxylin. After dehydration, sections were mounted with malinol.

\section{Quantification}

Sections were examined at $400 \times$ magnification. The numbers of positive and negative tumor cell nuclei in the $4 \times 4$ central part of a $10 \times 10$ grid inserted in one of the oculars were counted. Adjacent microscopical fields were examined until 1,000 or more 


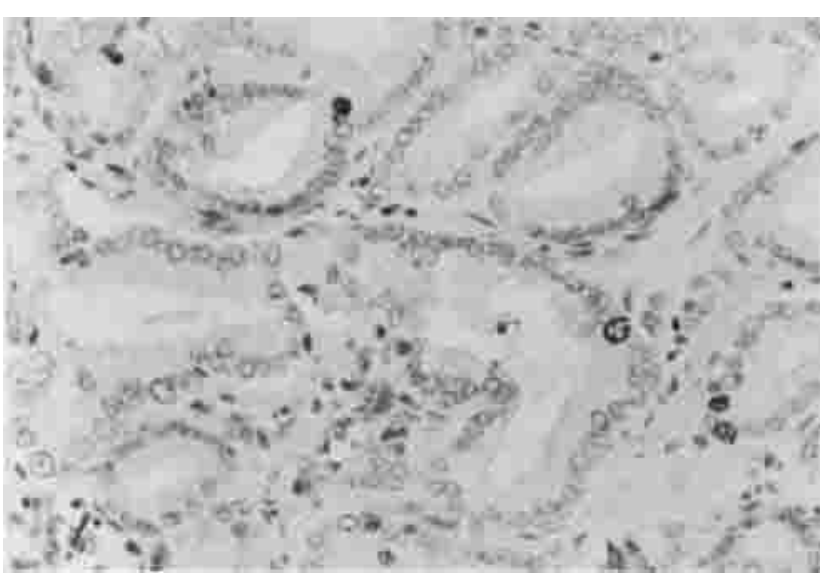

Fig. I. Well-differentiated adenocarcinoma in a tissue section of a 16-year-old radical prostatectomy stained with MIB-I. $\times 270$.

cells were counted. Cells with an apparent brown staining of the nucleus and well-demarcated nucleoli were judged positive. Scores are presented as percentages of cells counted. Spearman's rank correlations were calculated since the data were not normally distributed. For statistical confirmation the Student's t-test was performed using the software package SPSS 4.01 (Statistical Package for Social Sciences, SPSS, Inc., Chicago, IL).

\section{RESULTS}

\section{Immunostaining of Prostatectomy Specimens}

Figure 1 shows MIB-1 staining in a 16-year-old prostatectomy specimen. Although variations in staining intensity were observed, positive and negative cells were generally easy to identify. Occasionally cytoplasmic staining was observed. Detachment of parts of the prostatectomy sections from the glass slide was seen, especially in sections containing the (fatty) periprostatic tissue. The risk of detachment decreased when the slides, prior to antigen retrieval, were kept overnight at $60^{\circ} \mathrm{C}$. This procedure did not alter the immunoreactivity for MIB-1.

\section{Immunostaining of Prostatic Cancer Cell Lines}

Hormonal manipulation of the PC-82 tumorbearing mice resulted in tumors with various growth rates, which were clearly reflected by the MIB-1-, frozen Ki-67 (fKi-67)-, paraffin Ki-67 (pKi-67)-, and BrdU-defined proliferative activities (data not shown). Intensity of MIB-1 staining was in general more pronounced than intensity of $\mathrm{fKi}-67$ and pKi-67 staining. Weak nuclear MIB-1 staining could still be observed when the antibody was diluted 1:5,000 $(0.04 \mu \mathrm{g} / \mathrm{ml})$. Ki-67 staining decreased at a concentration of $3.96 \mu \mathrm{g} / \mathrm{ml}$ (1:50 dilution). Only little intratumoral variation in the dispersion of positive nuclei was observed. MIB-1 scores ranged from 0.1$25.7 \%$ (mean $11.6 \%$ ), fKi-67 scores ranged from $0.2-6.8 \%$ (mean 2.9\%), pKi-67 scores ranged from $0.6-18.5 \%$ (mean $6.7 \%$ ), and BrdU scores ranged from $0.0-7.5 \%$ (mean $2.4 \%$ ). Figure 2 shows fKi-67 staining (Fig. 2A), pKi-67 staining (Fig. 2B), and MIB-1 staining (Fig. 2C) in sections taken from one PC-82 tumor. In PC-82 tissues a highly significant correlation was found between MIB- 1 and $\mathrm{fKi}-67$ scores $(\mathrm{r}=0.86, P<0.001, \mathrm{n}=21)$, and between MIB-1 and pKi-67 scores $(\mathrm{r}=0.90, P<0.001, \mathrm{n}=25)$, as depicted in Figure 3. Relatively weak correlations were found between MIB-1 scores and BrdU-uptake, as shown in Figure $4(\mathrm{r}=0.70, P<0.001, \mathrm{n}=24)$, and between $\mathrm{fKi}-67$ scores and BrdU-uptake $(\mathrm{r}=0.44, P$ $=0.052, \mathrm{n}=20$ ). The correlation between $\mathrm{fKi}-67$ and pKi-67 scores was $0.77(P<0.001, \mathrm{n}=21)$. MIB-1 scores exceeded both the $\mathrm{fKi}-67$ scores (linear regression coefficient $\beta=3.67,95 \%$ confidence interval (CI): $2.87-4.47)$ and the pKi-67 scores $(\beta=1.57, \mathrm{CI}$ : 1.28-1.86). pKi-67 scores were double the fKi-67 scores $(\beta=2.03, \mathrm{CI}: 1.31-2.75)$.

The acetone-fixed LNCaP cultures did not require antigen retrieval prior to application of MIB-1. The growth-inhibiting effect of androgen depletion on the LNCaP cells was clearly reflected by a loglinear decline of Ki-67 and MIB-1 scores, representing the exit of cells from the cell cycle (Fig. 5). The MIB-1 and $\mathrm{Ki}-67$ scores observed in LNCaP cultures were generally larger than those observed in PC-82 tissue sections, and ranged from 16-70\% (mean, 39.6) for MIB-1, and from 7-41\% (mean, 19.8) for Ki-67. MIB-1 scores were almost double the Ki-67 scores $(\beta=1.81$, CI: 1.44-2.18), and the correlation coefficient was $0.84(P<0.001, \mathrm{n}=15)$.

\section{DISCUSSION}

The present study was conducted to compare the novel proliferation marker MIB-1 with frozen tissuebased Ki-67 (fKi-67), paraffin tissue-based Ki-67 (pKi-67), and BrdU uptake. This was achieved by immunostaining samples derived from hormonally manipulated PC-82 tumors and LNCaP cell cultures with the different antibodies $[1,5,7,8]$. In LNCaP cultures only Ki-67 and MIB-1 were studied. MIB-1 staining was also studied in archival radical prostatectomy specimens.

Antigen retrieval is essential for immunostaining with the MIB-1 or the Ki-67 (pKi-67) antibodies when applied to paraffin-embedded tissue sections. As found by others [19], application of MIB-1 without antigen retrieval only stained mitotic cells (not shown). The mechanism of antigen retrieval remains unclear as yet, but it has been suggested that the 

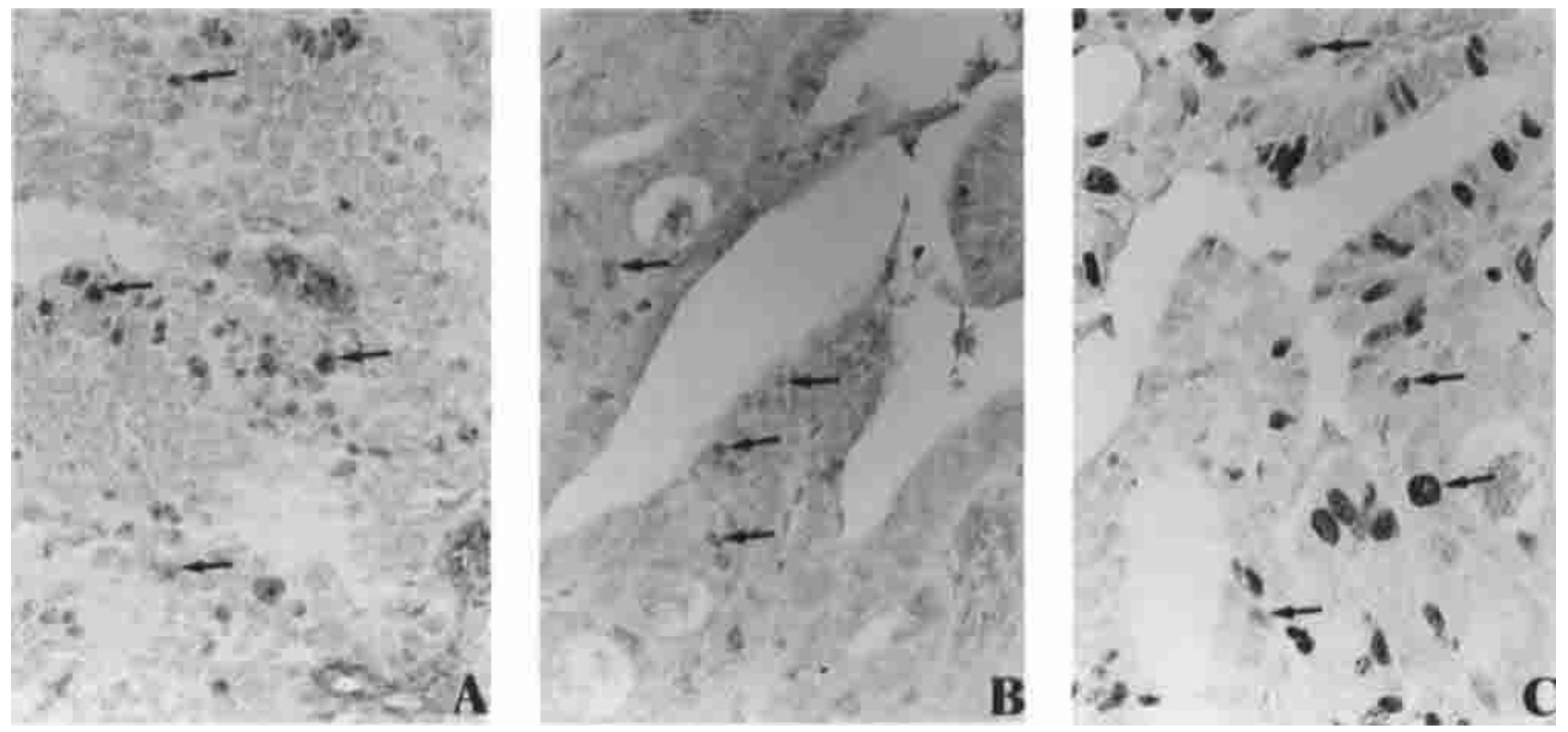

Fig. 2. Immunostaining of a PC-82 tumor sample (grown in a hormonally untreated mouse). A: Fresh-frozen section, Ki-67 (fKi-67). B: Paraffin-embedded section, Ki-67 (pKi-67). C: Paraffinembedded section, MIB-I $(\times 270)$. Some positive nuclei are indicated with arrows.

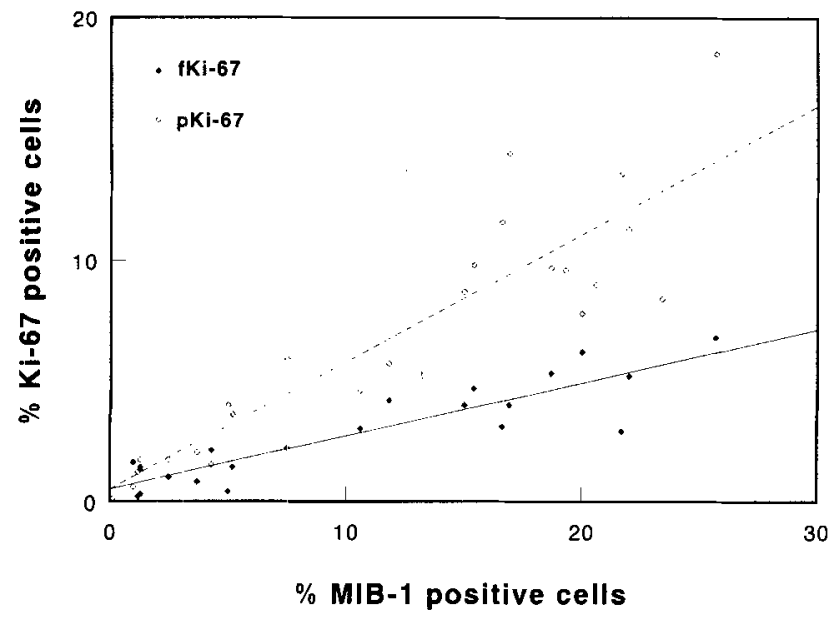

Fig. 3. Correlations between MIB-I scores and the respective fKi-67 (frozen tissue-based Ki-67) scores and pKi-67 (paraffin tissue-based $\mathrm{Ki}-67$ ) scores, assessed on PC-82 tumor samples ( $\mathrm{n}=$ 21). Note the difference in scaling of the axes. Regression lines: fKi-67 (solid line), pKi-67 (dotted line).

formalin-induced protein crosslinkings are broken with this procedure, thus unmasking the epitopes of the various antigens [6]. In the present study MIB-1 staining could still be observed in a 16-year-old prostatectomy specimen. Cattoretti et al. [19] detected MIB-1 reactivity in a 60-year-old Zenkers' fixed lymph node. Cytoplasmic staining was occasionally observed in some of the prostatectomy specimens. A similar cytoplasmic staining has also been described

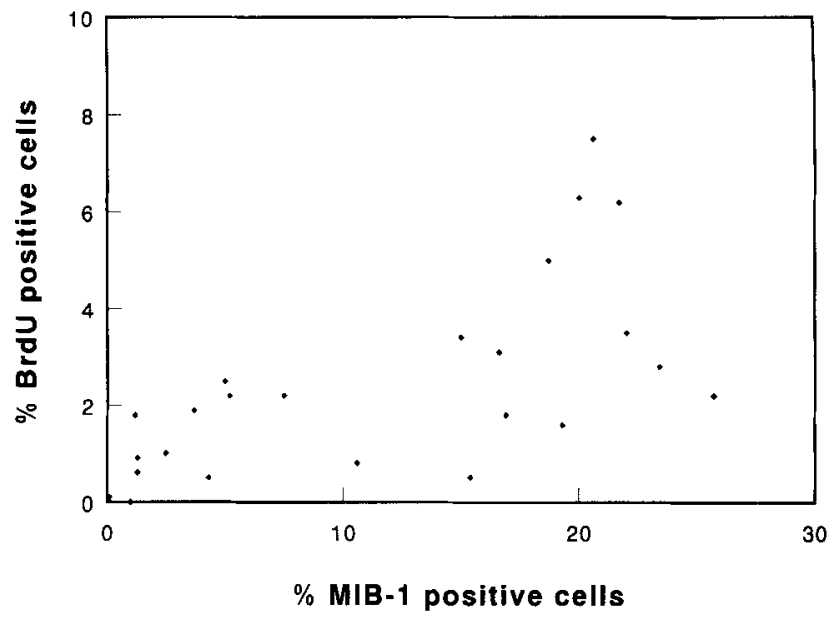

Fig. 4. Correlation between MIB-I scores and BrdU-uptake in 24 PC-82 tumors. Note the difference in scaling of the axes.

in prostatic tissues stained by $\mathrm{Ki}-67$, but appears not to be associated with proliferation [20]. fKi-67, pKi67, and especially MIB-1 staining were not always equal in intensity, as Figure 2 shows. This may complicate the distinction of positive and negative cells. In the present study, cells were scored positive only when both nuclear and nucleolar staining were visible. If cells showing only one of these patterns were included, scores would have been higher in a number of the sections.

Strong and statistically significant correlations were found between MIB-1 and fKi-67 scores ( $r=$ 


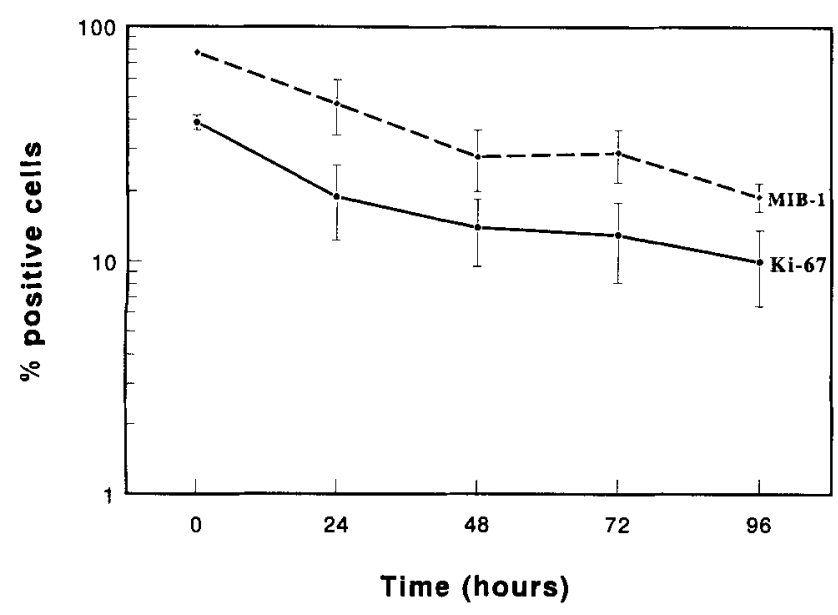

Fig. 5. The relation of MIB-I (dotted line) and Ki-67 scores (solid line) to time in a time-course experiment with hormone responsive LNCaP cells following androgen withdrawal at day 0 (mean \pm SD).

0.86, $P<0.001)$, between MIB-1 and pKi-67 scores $(\mathrm{r}=0.90, P<0.001)$ in PC-82 tumors (Fig. 3), and between MIB-1 and Ki-67 scores $(\mathrm{r}=0.84, P<0.001)$ in LNCaP cultures (Fig. 5). Surprisingly, MIB-1 scores exceeded both the fKi-67 scores $(\beta=3.67)$ and the pKi-67 scores $(\beta=1.57)$ in PC-82 sections. The methodological differences between the fKi-67 and MIB-1 staining procedures probably partially account for this discrepancy. However, the staining procedures were identical for $\mathrm{Ki}-67$ and MIB-1 applied to paraffin PC-82 sections $(\beta=1.57)$ and LNCaP cultures $(\beta=$ 1.81). Still, a marked difference was observed in both cases as demonstrated by the regression coefficients. The described intensity difference between MIB-1 and Ki-67 labelling might partially account for this discrepancy. McCormick et al. [21] have also shown a close relationship between MIB-1 and Ki-67 scores. However, based upon other types of tissue, they did not describe the discrepancy found in the present study. It has very recently been shown that the nuclear $\mathrm{Ki}-67$ protein, i.e., the protein recognized by Ki-67, can exist free or associated with double-strand DNA [22]. This study demonstrated that, in contrast to $\mathrm{Ki}-67$, MIB-1 recognizes the free protein. Moreover, the affinity of MIB-1 for the DNA Ki-67 protein complex largely exceeds the affinity of $\mathrm{Ki}-67$ for that complex [22]. This indicates that binding of the $\mathrm{Ki}-67$ protein to the DNA modulates its conformation, which makes it an antigen for both Ki-67 and MIB-1. Since MIB-1 was raised against recombinant expressed $\mathrm{Ki}-67$ protein, it was to be expected that MIB-1 would also recognize free Ki- 67 protein. These results provide at least one plausible explanation for the differences between the $\mathrm{Ki}-67$ and MIB-1 scores found in the present study. Furthermore, weak nuclear staining could still be observed when MIB-1 was applied at a dilution of $1: 5,000(0.04 \mu \mathrm{g} / \mathrm{ml})$, whereas nuclear Ki-67 staining decreased at a dilution of 1:50 (3.64 $\mu \mathrm{g} / \mathrm{ml})$.

Expectedly, BrdU pulse labeling scores are smaller than Ki-67 and MIB-1 scores [9,23]. Van Dierendonck et al. [24] have shown that Ki-67 scores cannot automatically be used to determine the growth fraction of a tumor. Therefore, the relatively weak correlations found between Ki-67 and BrdU, and between MIB-1 and BrdU, are not surprising. Sasaki et al. [9] described a correlation coefficient of 0.89 between $\mathrm{Ki}-67$ and BrdU scores in 20 malignant human tumors. The proliferation scores in their study $(1.9-37.5 \%$ for $\mathrm{Ki}-67$ and $1.6-23.4 \%$ for $\mathrm{BrdU}$ ) were generally larger than the scores found in the present study. In a study of Van Weerden et al. [23] using the PC-82 tumor model, the correlation between $\mathrm{Ki}-67$ and $\mathrm{BrdU}$ scores was comparable to that found in the present study. The clinical use of BrdU uptake is hampered as administration of BrdU to a patient may cause acute toxic reactions and/or chromosomal abnormalities $[25,26]$.

In conclusion, MIB-1 is a promising antibody and allows for the detection of very small amounts of the $\mathrm{Ki}-67$ antigen in routinely processed, paraffin-embedded archival tissues. MIB-1 might be of special value in tumors with relatively small growth fractions, such as prostatic carcinomas. At our institution a retrospective study to determine the prognostic value of MIB-1 in prostate cancer patients is currently in progress.

\section{ACKNOWLEDGMENTS}

The skillful technical advice of P.J.A. Jansen, Department of Pathology, Erasmus University, is greatly appreciated.

\section{REFERENCES}

1. Gerdes J, Schwab U, Lemke H, Stein H: Production of a mouse monoclonal antibody reactive with a human nuclear antigen associated with cell proliferation. Int J Cancer 31:13-20, 1983.

2. Gerdes J, Lemke H, Baisch H, Wacker HH, Schwab U, Stein H: Cell cycle analysis of a cell proliferation-associated human nuclear antigen defined by the monoclonal antibody Ki-67. J Immunol 133:1710-1715, 1984.

3. Oomens EH, van Steenbrugge GJ, van der Kwast TH, Schroder FH: Application of the monoclonal antibody $\mathrm{Ki}-67$ on prostate biopsies to assess the growth fraction of human prostatic carcinoma. J Urol 145:81-85, 1991.

4. Brown DC, Gatter KC: Monoclonal antibody Ki-67: its use in histopathology. Histopathology 17:489-503, 1990.

5. Key G, Becker MHG, Baron B, Duchrow M, Schlueter 
C, Flad H-D, Gerdes J: New Ki-67 equivalent murine monoclonal antibodies (MIB 1-3) generated against bacterially expressed parts of the $\mathrm{Ki}-67 \mathrm{cDNA}$ containing three 62 base pair repetitive elements encoding for the Ki-67 epitope. Lab Invest 68:629-636, 1993.

6. Shi SR, Key ME, Kalra KL: Antigen retrieval in formalin-fixed, paraffin-embedded tissues: An enhancement method for immunohistochemical staining based on microwave oven heating of tissue sections. J Histochem Cytochem 39:741-748, 1991.

7. Cuevas E, Jones DB, Wright DH: Immunohistochemical detection of tumour growth fraction (Ki-67 antigen) in formalin-fixed and routinely processed tissues. J Pathol 169:477-478, 1993.

8. Schutte B, Reynders MM, Bosman FT, Blijham GH: Studies with anti-bromodeoxyuridine antibodies: II. Simultaneous immunocytochemical detection of antigen expression and DNA synthesis by in vivo labeling of mouse intestinal mucosa. J Histochem Cytochem 35: 371-374, 1987.

9. Sasaki K, Matsumura K, Tsuji T, Shinozaki F, Takahashi M: Relationship between labeling indices of Ki-67 and BrdUrd in human malignant tumors. Cancer 62 : 989-993, 1988.

10. Riccardi A, Danova M, Wilson G, Ucci G, Dormer P, Mazzini G, Brugnatelli S, Girino M, McNally NJ, Ascari $\mathrm{E}$ : Cell kinetics in human malignancies studied with in vivo administration of bromodeoxyuridine and flow cytometry. Cancer Res 48:6238-6245, 1988.

11. Nemoto R, Uchida K, Shimazui T, Hattori K, Koiso K, Harada M: Immunocytochemical demonstration of $S$ phase cells by anti-bromodeoxyuridine monoclonal antibody in human prostate adenocarcinoma. J Urol 141: 337-340, 1989.

12. Hoehn $W$, Schroeder FH, Riemann JF, Joebsis AC, Hermanek P: Human prostatic adenocarcinoma: some characteristics of a serially transplantable line in nude mice (PC 82). Prostate 1:95-104, 1980.

13. Horoszewicz J, Leong $S$, Chu $T$, Wasjman $Z$, Friedman M, Papsidero L, Kim U, Chiu L, Kaliatis S, Arya S, Sandberg A: The LNCaP cell line-A new model for studies on human prostatic carcinoma. Prog Clin Biol Res 37:115-132, 1980.

14. Van Steenbrugge GJ, Groen M, Romijn JC, Schroeder FH: Biological effects of hormonal treatment regimes on a transplantable human prostatic tumor line (PC-82). J Urol 131:812-817, 1984.

15. Horoszewicz IS, Leong SS, Kawinski E, Karr J, Rosenthal H, Chu TM, Mirand EA, Murphy GP: LN$\mathrm{CaP}$ model of human prostatic carcinoma. Cancer Res 43:1809-1818, 1983.
16. Gallee MP, van Steenbrugge GJ, ten Kate FJ, Schroeder $\mathrm{FH}$, van der Kwast TH: Determination of the proliferative fraction of a transplantable, hormone-dependent, human prostatic carcinoma (PC-82) by monoclonal antibody Ki-67: potential application for hormone therapy monitoring. JNCI 79:1333-1340, 1987.

17. Maddox PH, Jenkins D: 3-Aminopropyltriethoxysilane (APES): A new advance in section adhesion. J Clin Pathol 40:1256-1257, 1987.

18. Van Steenbrugge GJ, van Uffelen CJ, Bolt J, Schroder FH: The human prostatic cancer cell line LNCaP and its derived sublines: An in vitro model for the study of androgen sensitivity. J Steroid Biochem Mol Biol 40: 207-214, 1991.

19. Cattoretti G, Becker MHG, Key G, Duchrow M, Schluter CGJ, Gerdes J: Monoclonal antibodies against recombinant parts of the ki 67 antigen (MIB-1 and MIB-3) detect proliferating cells in microwave-processed formalin-fixed paraffin sections. J Pathol 168: 357-363, 1992.

20. Gallee MP, Visser de Jong E, ten Kate FJ, Schroeder FH, van der Kwast TH: Monoclonal antibody Ki-67 defined growth fraction in benign prostatic hyperplasia and prostatic cancer. J Urol 142:1342-1346, 1989.

21. McCormick D, Chong H, Hobbs C, Datta C, Hall PA: Detection of the $\mathrm{Ki}-67$ antigen in fixed and wax-embedded sections with the monoclonal antibody MIB1. Histopathology 222:355-360, 1993.

22. Lopez F, Belloc F, Lacombe F, Dumain P, Reiffers I, Bernard P, Boisseau MR: The labeling of proliferating cells by Ki67 and MIB-1 antibodies depends on the binding of a nuclear protein to the DNA. Exp Cell Res 210:145-153, 1994.

23. Van Weerden WM, Moerings EP, van Kreuningen A, de Jong FH, van Steenbrugge GJ, Schroeder FH: Ki-67 and BrdU incorporation as markers of proliferative activity in human prostate tumor models. Cell Prolif 26: 67-75, 1993.

24. Van Dierendonck JH, Keijzer R, van de Velde CJ, Cornelisse CJ: Nuclear distribution of the $\mathrm{Ki}-67$ antigen during the cell cycle: Comparison with growth fraction in human breast cancer cells. Cancer Res 49:2999-3006, 1989.

25. Morstyn G, Hsu SM, Kinsella T, Gratzner H, Russo A, Mitchell JB: Bromodeoxyuridine in tumors and chromosomes detected with a monoclonal antibody. J Clin Invest 72:1844-1850, 1983.

26. Morris SM: The genetic toxicology of 5-bromodeoxyuridine in mammalian cells. Mutat Res 258:161-188, 1991. 